\title{
Influence of Wheel Profile Wear Coupled with Wheel Diameter Difference on the Dynamic Performance of Subway Vehicles
}

\author{
H. X. Li $\mathbb{D}^{1,2}$ A. H. Zhu ${ }^{1},{ }^{1,2}$ C. C. Ma, ${ }^{1,2}$ P. W. Sun, ${ }^{1,2}$ J. W. Yang $\mathbb{D}^{1,2}$ and K. Q. Zhang ${ }^{1,2}$ \\ ${ }^{1}$ Beijing Key Laboratory of Performance Guarantee of Urban Rail Transit Vehicles, \\ Beijing University of Civil Engineering and Architecture, Beijing 100044, China \\ ${ }^{2}$ School of Mechanical-Electronic and Vehicle Engineering, Beijing University of Civil Engineering and Architecture, \\ Beijing 100044, China \\ Correspondence should be addressed to A. H. Zhu; zhuaihua@bucea.edu.cn
}

Received 21 October 2020; Revised 23 April 2021; Accepted 29 May 2021; Published 10 June 2021

Academic Editor: Xiao-ting Rui

Copyright $\odot 2021 \mathrm{H}$. X. Li et al. This is an open access article distributed under the Creative Commons Attribution License, which permits unrestricted use, distribution, and reproduction in any medium, provided the original work is properly cited.

\begin{abstract}
In view of the coexistence of wheel profile wear (WPW) and wheel diameter difference (WDD) on an actual subway line, a dynamic analysis method based on coupling between WPW and equivalent in-phase WDD was proposed. Based on the measurements from a subway vehicle in operation on this line, dynamics modeling and calculations were performed for a single carriage of this vehicle. Later, the interaction between the effects of WPW and equivalent in-phase WDD on the vehicle dynamic performance was analyzed, and the dynamic response in the presence of coupled damage was compared between the outer and inner wheels. Furthermore, the difference in the dynamic response caused by different positions of the larger-diameter wheels (i.e., on the inner track or outer track) was analyzed for the case where equivalent in-phase WDD occurred between the front and rear bogies. The results show that when the vehicle ran on a straight line, the coupling between WPW and WDD reduced the vehicle's stability but improved its ride comfort. When the vehicle traveled on a curved line, it showed reductions in the lateral wheel/rail contact force, derailment coefficient, axle lateral force, and wear index if the outer wheels had a larger diameter. As a result, the deterioration of the vehicle's dynamic performance due to the increasing degree of WPW slowed down, and its curve negotiation performance improved. Meanwhile, the outer wheels had significantly greater lateral wheel/rail contact force, derailment coefficient, and wear index compared to the inner wheels. When a $-1 \mathrm{~mm}$ WDD was coupled with the worn wheel profile for $14 \times 10^{4}$ kilometers traveled, the dynamic performance indexes of the vehicle were close to or even exceeded the corresponding safety limits. The findings can provide technical support for subway vehicle maintenance.
\end{abstract}

\section{Introduction}

During subway operation, longitudinal and lateral wheel/rail forces will arise from traction and braking, as well as the centrifugal effect in the process of curve negotiation, resulting in various types of damage to wheels and rails. Moreover, due to growing subway traffic flow and train speed, frequent starting and braking, and the increasing number of small-radius curved lines, wheels are suffering increasingly severe damage. In particular, wheels are often subject to more diverse, complex damage rather than one damage type. The major types of wheel damage include wheel profile wear (WPW), wheel diameter difference (WDD), and tread peeling. WPW and WDD usually coexist as the most common coupled damage, which is difficult to solve, imposes high repair cost, and has a significant impact on the safety and comfort of subway vehicles. Therefore, studying the influence of WPW coupled with WDD on subway vehicle dynamics has practical significance.

For a subway vehicle in operation, its wheels are inevitably subject to tread and flange wear caused by wheel/rail contact and braking, resulting in changes in wheel profiles. As the distance traveled increases, the degree of wear tends to increase and wheel profiles tend to vary.

A great deal of research has investigated the influence of WPW on vehicle dynamics by theoretical, simulation, or experimental approaches. Cui et al. studied the influences of different wear forms on vehicle dynamics by field test 
combined with simulations and analysis and found that the false flange created by wheel wear would endanger the operational safety of the vehicle [1]. Lu et al. created a dynamic model for a Type B metro vehicle with Universal Mechanism (UM), a software package for simulation of multibody system dynamics, and analyzed the influence of wheel wear on vehicle dynamic performance and the characteristics of wheel/rail contact damage [2]. Yao et al. studied the effects of wheel wear on the dynamics performance of a high-speed train and suggested that the vehicle system's transverse stability index linearly decreased as the depth of wheel wear increased [3]. S. Pradhan et al. [4] investigated the influences of various stages of wheel wear on the dynamic responses such as curving performance and then evaluated the critical speed and ride comfort of the railway vehicle on the simulated test track to justify the maintenance schedule. Sun et al. simulated the multipoint contact and non-Hertzian contact between worn wheel and rail using a modified Kik-Piotrowski method. The wheel/rail normal vertical force, wheel/rail creep force, and contact patch shape predicted with this method are in good agreement with the results of contact calculation [5]. By measuring tread and rail profiles, Zong et al. analyzed the impact of equivalent conicity on the nonlinear critical speed of metro vehicles [6]. Shi et al. experimentally tested the dynamic performance of a high-speed train running at $300 \mathrm{~km} / \mathrm{h}$ and revealed that the vibration of axle box, frame, and car body tended to intensify gradually with increasing wheel wear [7]. Using a vehicle-turnout coupling dynamic model, Xiao et al. analyzed the dynamic response of a highspeed train with wheel wear when it passed a turnout. They found that wheel-rail wear caused an increase in wheel/rail vertical force and a decline in wheel/rail transverse force [8]. $\mathrm{Xu}$ et al. studied the influence of the increase in wheel wear on vehicle dynamics through simulation with SIMPACK, with wheel/rail contact being considered as the entry point. The results showed a marked decreasing trend in the vehicle's critical speed [9]. Xie et al. found that as the speed increased, the influence of wheel harmonic wear on vehicle stability became increasingly significant [10]. The stochastic model for vehicle-track systems provided by $\mathrm{Xu}$ and Zhai enables good analysis of dynamic response and reliability of a vehicle-track system in the presence of varying wheel wear and stochastic track irregularity [11]. Liu and Bruni investigated the influence of individual wheel profiles measured on a rail vehicle on the vehicle's dynamics in the context of multibody $(\mathrm{MB})$ simulations [12].

In terms of the effect of WDD on dynamic performance, Lyu et al. showed that when the initial WDD was large, cracks and localized wear occurred soon and always on wheelsets with smaller diameters, and they can deteriorate the dynamic performance of vehicles [13]. Sun et al. analyzed the influence of WDD on the stability, safety, and comfort of a vehicle traveling along a bridge by simulation and suggested that WDD should be strictly controlled for highspeed trains [14]. Jiang et al. constructed a nonlinear dynamic model for a metro vehicle and then calculated the critical speed, stability, safety, and wear power of the vehicle for different WDDs. The results showed that with the increase in coaxial WDD, the critical speed decreased sharply while the lateral stability and wear power increased significantly [15]. Yan et al. studied the influence of frontaxle WDD, rear-axle WDD, equivalent in-phase WDD, and equivalent antiphase WDD on the safety of a locomotive during motion on straight line and curved line [16]. Based on a high-speed train and 12\# turnout of a passenger dedicated line in China, Chen et al. developed a vehicle-turnout dynamic model and systematically analyzed the stability, safety, and ride comfort of a high-speed vehicle passing through a turnout for different types and magnitudes of WDD. They suggested that the operational limits for inphase and antiphase WDDs be set at $2 \mathrm{~mm}$ and $3 \mathrm{~mm}$, respectively and the limit for coaxial WDD above which primary and secondary maintenance is needed be set at $1.5 \mathrm{~mm}$ [17]. Based on an analysis of the types of WDD, Ma et al. discussed the influence of WDD on the stress state and movement of wheelsets [18]. He et al. suggested that WDD can lead to a significant increase in lateral wheel/rail contact force for a locomotive running on a straight line [19]. Wang et al. found that the yaw angle of wheelset, lateral displacement, wear power, and creep force of wheelset sharply increased with greater WDD [20]. Liu et al. analyzed the influence of coaxial WDD on a locomotive's dynamic performance. The results revealed that the coaxial WDD changed the position of wheel-rail contact and increased the equivalent stress of the rail, which could impair the locomotive's dynamic performance [21]. Based on an electric locomotive equipped with three-axle bogies, Zhang et al. investigated the influence of WDD at different axles on locomotive dynamic performance. The results showed that both derailment coefficient and wheel unloading rate increased with increasing WDD at the first axle and decreased with increasing WDD at the other two axles [22]. By analyzing the forces acting on a bogie with WDD, Chi et al. theoretically inferred that the existence of WDD changed the balance position of the wheelset center and thereby changed the wheel/rail contact relationship and affected the vehicle system's stability [23].

These researchers have looked at the influence of WPW or WDD on vehicle dynamics from various perspectives and offered insights into how to solve relevant dynamic performance problems. Research related to WPW focused mainly on how wear depth, harmonic wear, and crater wear affect vehicle dynamic performance, and research related to WDD emphasized the effect of the type and range of WDD.

However, most of these studies only considered the influence of a single type of wheel damage on vehicle dynamics, neglecting the coexistence of multiple damage types and the interaction between the effects of different damage types on vehicle dynamics. The present study analyzed the data on wheel damage measured on a specific subway line and found that WPW and equivalent in-phase WDD are the main types of wheel damage in vehicles running on this line. So, WPW and equivalent in-phase WDD were considered together to further analyze the influence of coupled wheel damage on vehicle dynamic performance.

Moreover, the existing research only considered front bogie, neglecting a real situation where both front and rear 
bogies have WDD. So, the present study considered the occurrence of equivalent in-phase WDD at the front and rear bogies and then analyzed the difference in dynamic response caused by different positions of the larger-diameter wheels, i.e., on the inner track or outer track.

Additionally, in vehicle dynamics modeling, these researchers only considered wheel damage in a single wheelset and set other wheelsets as standard ones. This cannot accurately reflect the actual characteristics of wheel damage. The present study not only considered the characteristics of damage in all wheels based on measured data but also compared the dynamic responses of the inner and outer wheels.

\section{Analysis of Measured Wheel Data}

A subway vehicle operating on a subway line has been tracked in this study. This vehicle consists of 6 carriages, each having 8 wheels. The profiles and diameters of these 48 wheels have been measured since the beginning of the vehicle's operation. The wheel profile and diameter data were collected when the distance traveled reached $5 \times 10^{4}, 8 \times 10^{4}$ and $14 \times 10^{4} \mathrm{~km}$.

2.1. Measured Wheel Profiles. Wheel/rail contact can be divided into three regions, as shown in Figure 1. Region A is the contact region between wheel tread and railhead. Wheel/ rail contact in this region usually occurs when a vehicle travels on a straight line or a large-radius curve. Region B is the region of contact between wheel flange and track corner, which often occurs when a vehicle runs on a small-radius curve. In region $\mathrm{C}$, wheel/rail contact is highly unlikely to occur.

The profiles of the subway vehicle's wheels were tracked and analyzed. It was found that wheel wear was located largely in region A, as shown in Figure 1. The wear in this region is called tread wear. The test vehicle in this study has 6 carriages, and 1 carriage was selected for dynamic modeling to allow for more time-efficient simulations and calculations. An analysis of the measurements found that the differences in maximum tread wear depth between the 6 carriages were about $10 \%$, and the worst wheel wear occurred in the No. 2 carriage. So, No. 2 carriage was selected for dynamics modeling. The measured profile of this carriage's 8 wheels was used for its dynamics model in order to allow the results to reflect its actual status.

Figure 2 illustrates the maximum tread wear depths in the 8 wheels measured when the distance traveled reached $5 \times 10^{4}, 8 \times 10^{4}$, and $14 \times 10^{4} \mathrm{~km}$. The left wheels were numbered $1,3,5$, and 7 , and the right ones were numbered 2 , 4,6 , and 8 .

In order to reduce cuspidal points on tread profile and prevent accumulation of errors during curve fitting, a data processor based on cubic spline interpolation algorithm was compiled in MATLAB software to smooth the wheel tread data [24]. The computational formula is

$$
y(x)=f(x)+\varepsilon(x), x \in[a, b],
$$

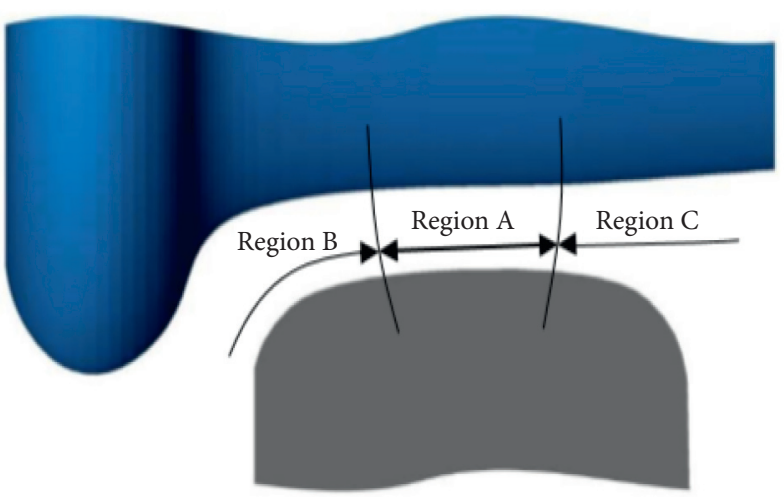

Figure 1: Wheel/rail contact regions.

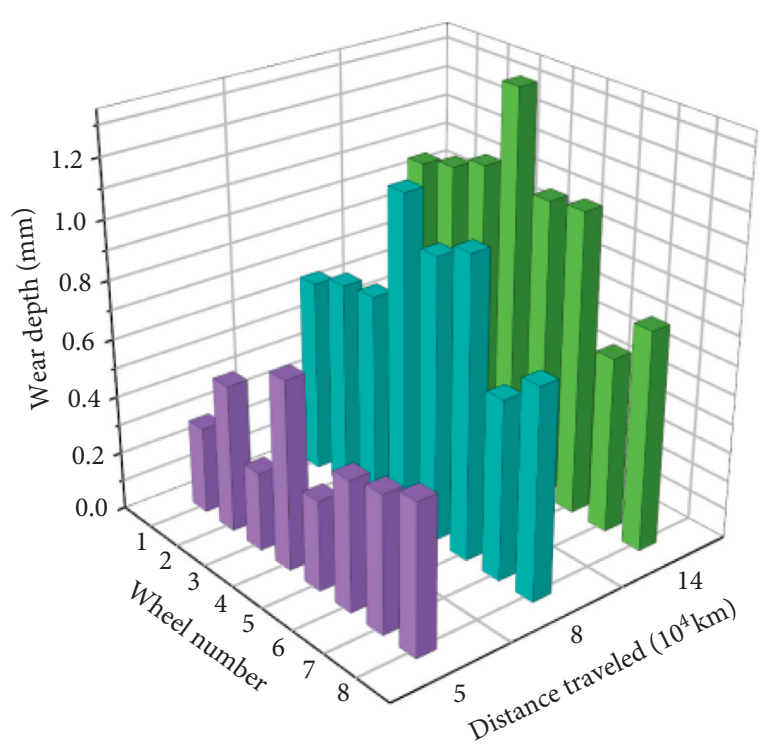

Figure 2: Measured tread wear depths.

where $f(x)$ is the cubic spline smooth curve, $\varepsilon(x)$ is the random error, $y(x)$ is the experimental data, and $[a, b]$ is the range of abscissa of the wheel profile.

Then, the 8 wheels' profiles for $5 \times 10^{4}, 8 \times 10^{4}$, and $14 \times 10^{4} \mathrm{~km}$ traveled shown in Figure 3 were used for subsequent modeling.

2.2. Analysis of the WDD Data. For a subway vehicle, the degree of wear varies between wheels due to the complex, variable conditions during actual operation. Figure 4 shows the four types of WDD for two-axle bogies, with " $v$ " at the top indicating the direction of vehicle movement. They are as follows: (I) front WDD (the left and right wheels on the front axle have different diameters), (II) rear WDD (the left and right wheels on the rear axle have different diameters), (III) equivalent in-phase WDD (the smaller-diameter wheels on the front and rear axles are on the same side), and (IV) equivalent antiphase WDD (the smaller-diameter wheels on the front and rear axles are on opposite sides) [25]. According to the literature 

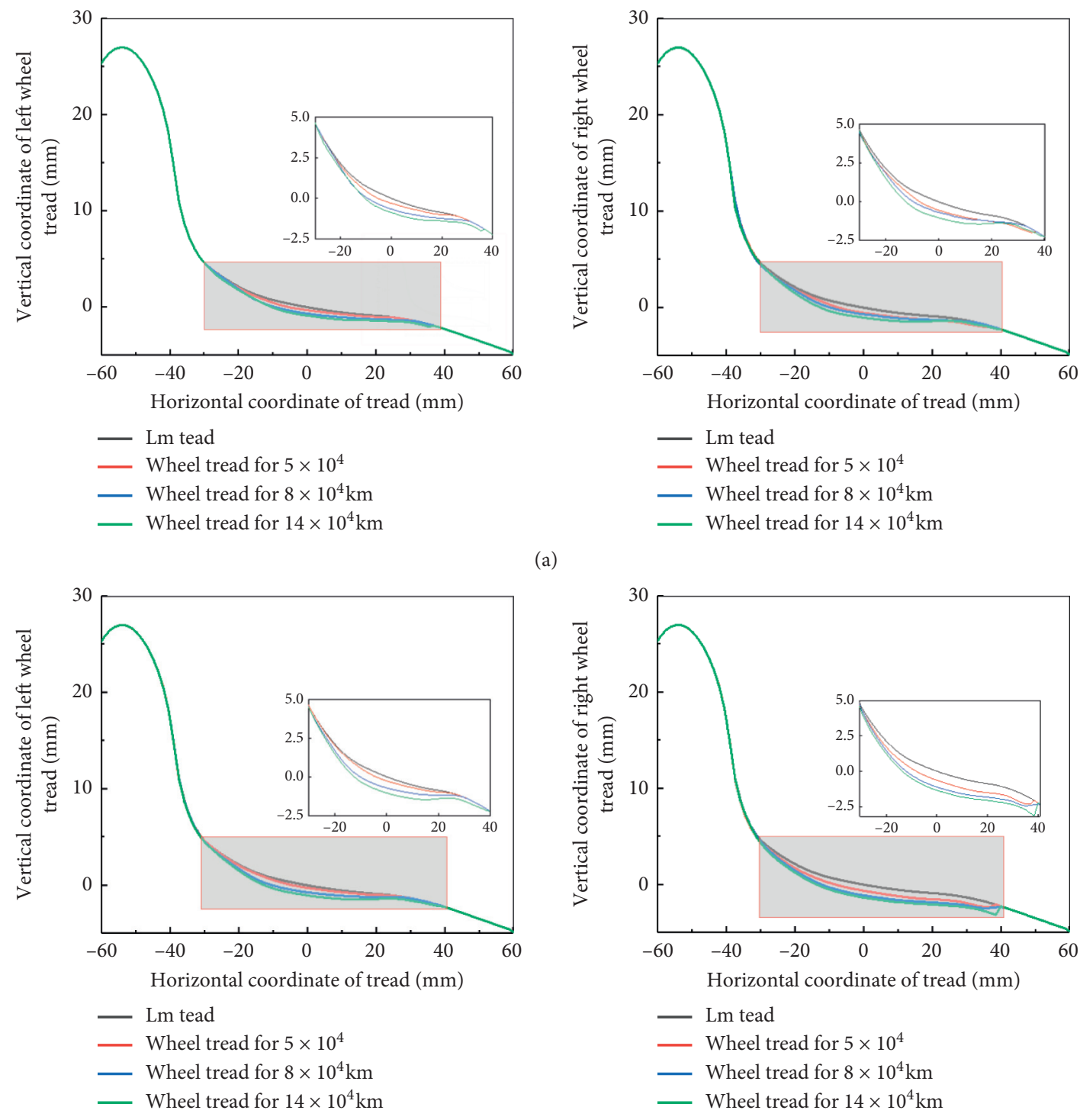

(b)
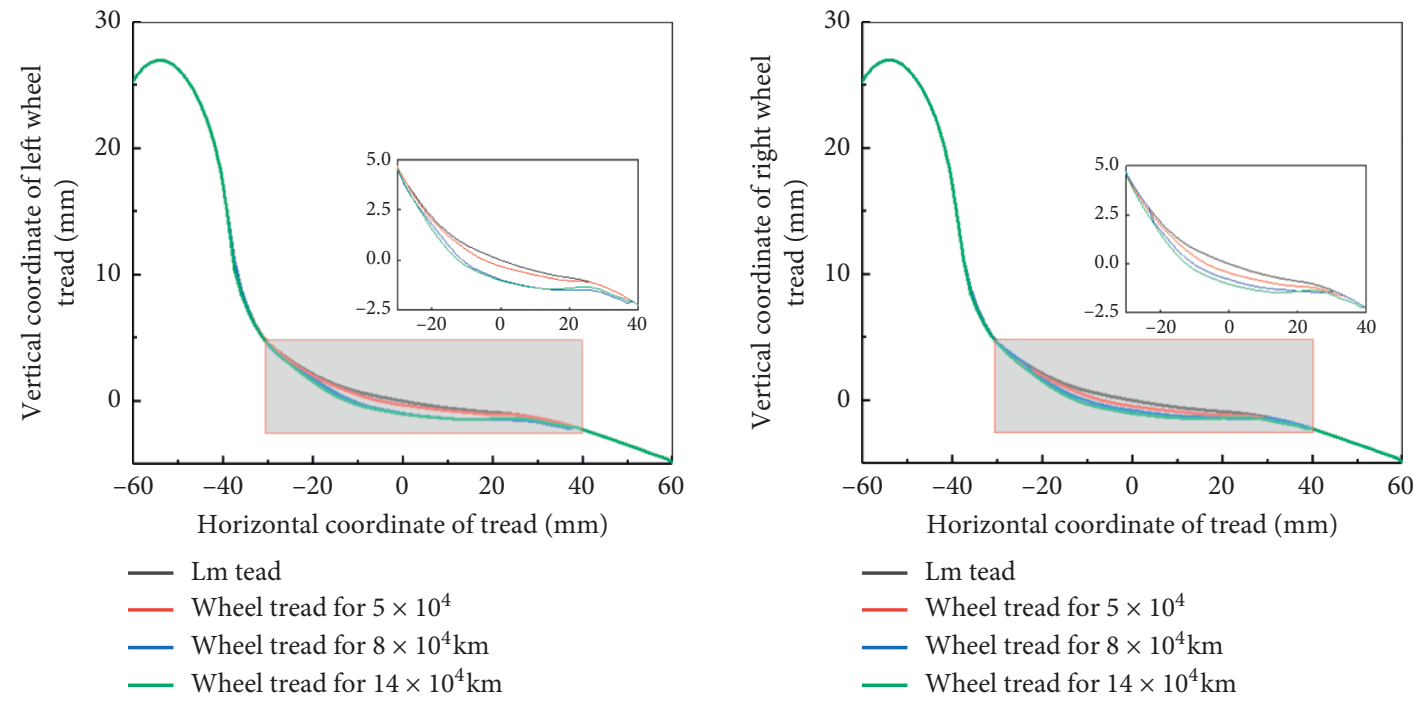

(c)

Figure 3: Continued. 

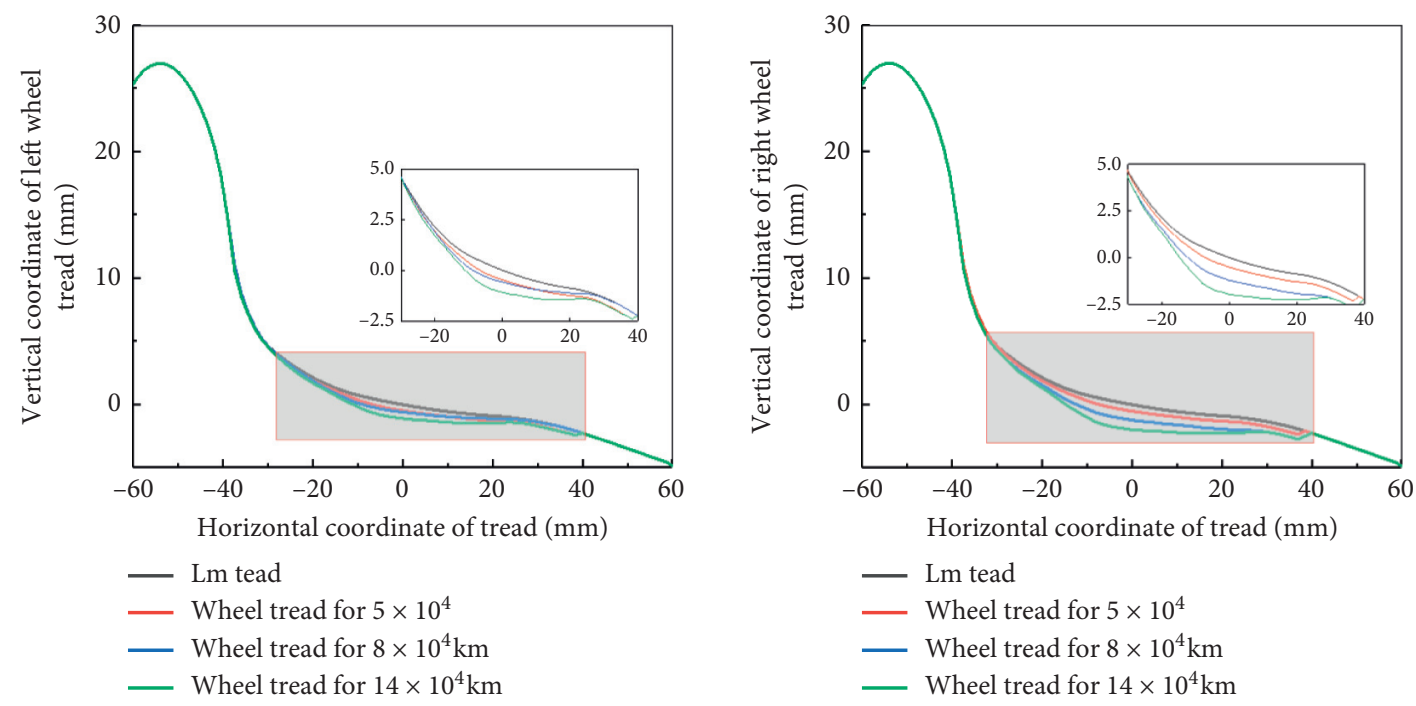

(d)

Figure 3: Measured wheel profiles. (a) First-axle wheel profiles. (b) Second-axle wheel profiles. (c) Third-axle wheel profiles. (d) Fourth-axle wheel profiles.
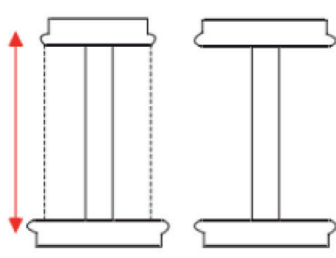

(a)

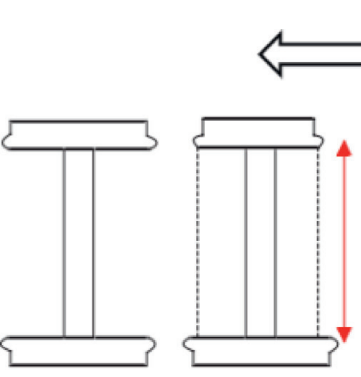

(b)

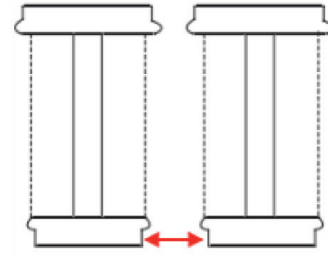

(c)

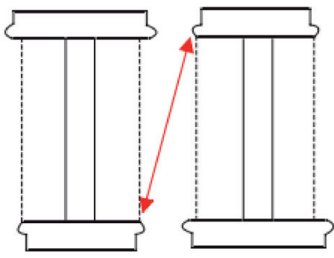

(d)

FIgURE 4: Types of WDD: (a) front WDD, (b) rear WDD, (c) equivalent in-phase WDD, and (d) equivalent antiphase WDD.

[26-27], of the four types of WDD, equivalent in-phase WDD has the greatest influence on the curve negotiation performance of vehicles.

The diameters of wheels of a subway vehicle were tracked. This wheel diameter measuring instrument is used for measuring the diameter of a wheel's rolling circle. It works by three-point indirect measurement and shows readings on a mechanical indicator, which allows users to get diameter reading directly. It is characterized by small measurement error, high indication stability, low weight, and ease of use.

An analysis of the measured diameter data reveals that there was equivalent in-phase WDD between the front and rear bogies of each carriage after a long-term operation on the same line. In other words, the smaller-diameter wheels of the front and rear bogies were on the same side, as illustrated in Figure 5. For this reason, equivalent in-phase WDD was applied to modeling to study its effect on vehicle dynamic performance.

WDD refers to the difference between the nominal rolling radii of the left and right wheels. A wheelset's diameter difference is defined by

$$
\Delta D=D_{\text {outer }}-D_{\text {inner }}
$$

where $D_{\text {inner }}$ is the diameter of the wheel on the inner track (inner wheel); $D_{\text {outer }}$ is the diameter of the wheel on the outer track (outer wheel); and $\Delta D<0$ indicates that the inner wheel diameter is greater than that of the outer wheel diameter.

According to a relevant regulation of China, a wheelset needs to be repaired when its coaxial diameter difference reaches $1 \mathrm{~mm}$. Given the possibility of machining error, the technical specification for wheelset assembly allows WDD of less than $0.3 \mathrm{~mm}$ [28]. Table 1 provides the values of equivalent in-phase WDD set in this study.

\section{Dynamics Models for the Vehicle- Track System}

3.1. Vehicle Dynamics Model. A vehicle dynamics model was constructed based on the parameters of the Type B vehicle tracked. It consists primarily of 1 vehicle body, 2 frames, 4 wheelsets, 8 axle boxes, and primary and secondary suspension systems. The vehicle body, frames, and wheelsets are 

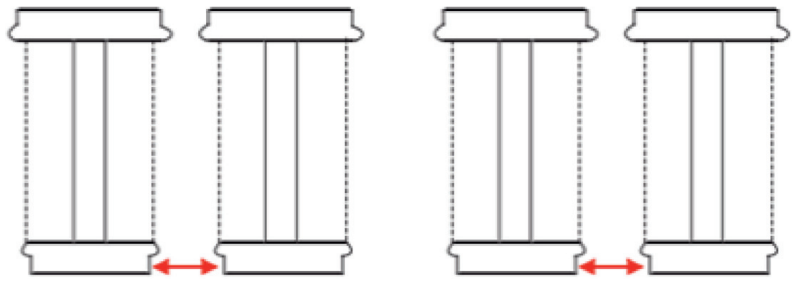

FIGURE 5: Equivalent in-phase WDD between the front and rear bogies.

TABLE 1: Wheel diameter difference setting.

\begin{tabular}{lccc}
\hline Condition & Left wheel (outer) diameter $(\mathrm{mm})$ & Right wheel (inner) diameter $(\mathrm{mm})$ & WDD $(\mathrm{mm})$ \\
\hline 1 & 839 & 840 & -1 \\
2 & 839.2 & 840 & -0.8 \\
3 & 839.5 & 840 & -0.5 \\
4 & 839.8 & 840 & -0.2 \\
5 & 840 & 840 & 0 \\
6 & 840 & 839.8 & 0.2 \\
7 & 840 & 839.5 & 0.5 \\
8 & 840 & 839.2 & 0.8 \\
9 & 840 & 839 & 1 \\
\hline
\end{tabular}

all treated as rigid bodies, and each has six degrees of freedom (DOFs), including surging, swaying, heaving, rolling, pitching, and yawing. The whole vehicle has 50 DOFs in total. The dynamic equation of motion for the vehicle is as follows [29]:

$$
M \ddot{X}+C \dot{X}+K X=P
$$

where $M, C$, and $K$ are the mass matrix, damping matrix, and stiffness matrix, respectively, for the vehicle system; $X$ is the generalized displacement; and $P$ is the generalized load.

The vehicle dynamics model is shown in Figure 6, and the main parameters of the vehicle are presented in Table 2 [30].

The track was simulated with standard UIC60 rail and German high-speed spectrum was applied for track excitation. The subway line was simulated with two line types: straight line and curved line, with each being $1000 \mathrm{~m}$ long in total. The curved line is C-shaped and composed of five parts, which are a straight segment, a transition curve, a circular curve, a transition curve, and a straight segment in sequence. The circular curve has a radius of $300 \mathrm{~m}$. The composition is shown in Table 3 . Moreover, the curved line was set as a right-turning line. Along the direction of vehicle movement, the left wheels were designated as the outer wheels and the right wheels as the inner wheels. If its direction was changed to leftturning because the wheel diameter difference changes symmetrically from $-1 \mathrm{~mm}$ to $1 \mathrm{~mm}$, the dynamic performance change rule is the same, and only the inner wheel and outer wheel are exchanged.

Based on the actual operational characteristics of the test line, variable velocity was set for the vehicle to simulate its acceleration, coasting, and deceleration, and the maximum velocity was set at $65 \mathrm{~km} / \mathrm{h}$. Then, the functional relationship between vehicle velocity $v$ and distance traveled $s$ is obtained:

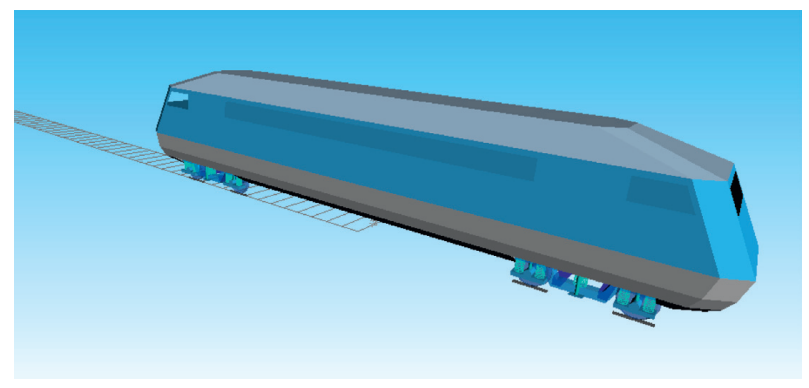

Figure 6: Vehicle dynamics model.

$v(s)= \begin{cases}-2.76 \times 10^{-4} s^{2}+0.276 s, & (0<s \leq 360 ; 630<s \leq 1000), \\ 65, & (360<s \leq 630) .\end{cases}$

The piecewise velocity function $v(s)$ above can be used to simulate the process of velocity change as the initially static vehicle starts by traction, then coasts, and finally brakes to stop along a $1000 \mathrm{~m}$ curved line.

Hertz's theory is used for solving normal contact problems, and Kalker's simplified theory and the corresponding FASTSIM algorithm are applied to calculate the distribution and magnitude of the tangential creep forces within the contact patch.

3.2. Model of Coupling between WPW and WDD. During modeling of vehicle dynamics, the wheel wear data measured when the distance traveled reached $5 \times 10^{4}, 8 \times 10^{4}$, and $14 \times 10^{4} \mathrm{~km}$ were imported into the wheel profile database to obtain worn wheel profiles, which are represented by $S 1, S 2$, and $S 3$, respectively (Table 4 ). Then, worn wheel profile models were constructed by applying the profile data shown in Figure 3 to the eight wheels of each carriage. 
TABLE 2: Main parameters of the vehicle.

\begin{tabular}{lcc}
\hline Parameter & Value & Unit \\
\hline Vehicle body mass & 33859 & $\mathrm{~kg}$ \\
Vehicle body's moment of inertia in roll & 73105 & $\mathrm{~kg} \cdot \mathrm{m}^{2}$ \\
Vehicle body's moment of inertia in pitch & 1157173 & $\mathrm{~kg} \cdot \mathrm{m}^{2}$ \\
Vehicle body's moment of inertia in yaw & 1171980 & 2103 \\
Frame mass & 1333 & $\mathrm{~kg} \cdot \mathrm{m}^{2}$ \\
Frame's moment of inertia in roll & 864 & $\mathrm{~kg} \cdot \mathrm{m}^{2}$ \\
Frame's moment of inertia in pitch & 2131 & $\mathrm{~kg} \cdot \mathrm{m}^{2}$ \\
Frame's moment of inertia in yaw & 1018 & $\mathrm{~kg} \cdot \mathrm{m}^{2}$ \\
Wheelset mass & 546.7 & 75 \\
Wheelset's moment of inertia in roll & $\mathrm{kg} \cdot \mathrm{m}^{2}$ \\
Wheelset's moment of inertia in pitch & 546.7 & 1.3 \\
Wheelset's moment of inertia in yaw & 1840 \\
Primary suspension system's vertical stiffness & $25(0.15 \mathrm{~m} / \mathrm{s})$ & $\mathrm{kg} \cdot \mathrm{m}^{2}$ \\
Primary suspension system's vertical damping coefficient & $\mathrm{MN} / \mathrm{m}$ \\
Secondary suspension system's vertical damping coefficient & $\mathrm{N} \cdot \mathrm{s} / \mathrm{m}$ \\
Secondary suspension system's lateral damping coefficient & $\mathrm{kN} \cdot \mathrm{s} / \mathrm{m}$ \\
\hline
\end{tabular}

TABle 3: C-shaped line composition.

\begin{tabular}{lcc}
\hline Number & Line type & Length $(\mathrm{m})$ \\
\hline 1 & Straight line & 245 \\
2 & Transition curve & 55 \\
3 & R300 circular curve & 400 \\
4 & Transition curve & 55 \\
5 & Straight line & 245 \\
\hline
\end{tabular}

TABLE 4: Worn wheel profiles for different distances traveled.

\begin{tabular}{lccc}
\hline Distance traveled & $5 \times 10^{4} \mathrm{~km}$ & $8 \times 10^{4} \mathrm{~km}$ & $14 \times 10^{4} \mathrm{~km}$ \\
\hline Worn wheel profile & $S 1$ & $S 2$ & $S 3$ \\
\hline
\end{tabular}

Later, the WDD model was built by setting wheel diameters using the Geometry module in SIMPACK. In accordance with Table 1, the WDD was set at 9 values, including $-1 \mathrm{~mm},-0.8 \mathrm{~mm},-0.5 \mathrm{~mm},-0.2 \mathrm{~mm}, 0 \mathrm{~mm}$, $0.2 \mathrm{~mm}, 0.5 \mathrm{~mm}, 0.8 \mathrm{~mm}$, and $1 \mathrm{~mm}$.

After that, the coupling between WPW and WDD was modeled by applying the diameter values to corresponding worn wheel profiles in the vehicle dynamics model.

3.3. Validation of the Vehicle Dynamics Model. Ride comfort is an important factor considered in assessing the comfort of vehicles. Ride comfort index and vibration acceleration are widely adopted to evaluate the dynamic performance of vehicles around the world [31]. The ride comfort index of a vehicle, $W$, can be calculated as follows [32].

$$
W=0.896 \sqrt[10]{\frac{a^{3}}{f} F(f)},
$$

where $a$ is the vibration acceleration $\left(\mathrm{cm} / \mathrm{s}^{2}\right) ; f$ is the frequency of vibration $(\mathrm{Hz})$; and $F(f)$ is the correction factor related to $f$.
After the vehicle dynamics model was constructed based on the parameters of the actual vehicle and the line status, the vertical acceleration and ride comfort index of the model were calculated. The results were then compared with the measured data to verify the reliability of the model so as to ensure accurate results of the subsequent simulation.

A vibration test was conducted on the studied vehicle, and the test data were collected with COINV DASP, a software package developed by the China Orient Institute of Noise and Vibration. In accordance with the Railway vehicles, specification for evaluation of the dynamic performance and accreditation test (GB5599-1985), an accelerometer was mounted on the floor to the left of the front bogie ( $1 \mathrm{~m}$ from the bogie pivot center) to measure the vehicle's acceleration and the sampling frequency was $1024 \mathrm{~Hz}$. The acceleration data obtained are plotted in Figure 7 .

The simulated acceleration was compared with the measured acceleration and then the ride comfort index was calculated from the simulated and measured data using equation (5).

As can be seen in Table 5, the maximum peak vertical acceleration obtained by simulation is slightly smaller than the measured value. The reason is that some parts of the vehicle's structure were simplified in modeling. However, the amplitudes of the simulated and measured values varied in similar ways. The simulated time of the maximum peak is quite close to the measured value, suggesting the high reliability of the vehicle dynamics model proposed in the paper.

\section{Influence of WPW Coupled with WDD on the Dynamic Performance of a Vehicle Running on a Straight Line}

Three worn wheel profiles for $5 \times 10^{4}, 8 \times 10^{4}$, and $14 \times 10^{4} \mathrm{~km}$ traveled (see Figure 3 and Table 4) and nine WDDs between $-1 \mathrm{~mm}$ and $+1 \mathrm{~mm}$ (Table 1) were set based on the measured data from the test vehicle. Later, 


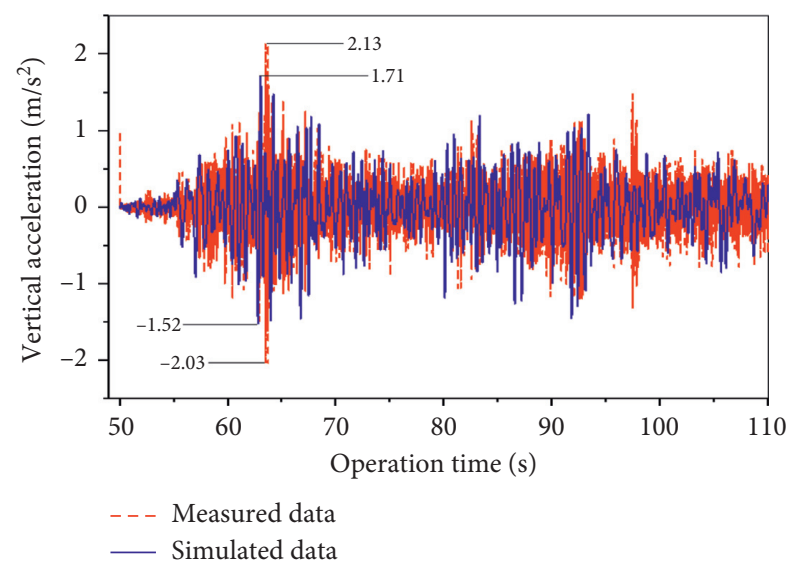

Figure 7: Comparison of vertical acceleration.

TABLe 5: Comparison of simulated and measured data.

\begin{tabular}{lccc}
\hline $\begin{array}{l}\text { Acceleration } \\
\text { value }\end{array}$ & $\begin{array}{c}\text { Measured } \\
\text { value } A(\mathrm{~s})\end{array}$ & $\begin{array}{c}\text { Simulated } \\
\text { value } B(\mathrm{~s})\end{array}$ & $\begin{array}{c}\text { Rate of change } \\
100 x(A-B) / A \\
(\%)\end{array}$ \\
\hline $\begin{array}{l}\text { Maximum peak } \\
\text { vertical }\end{array}$ & 2.13 & 1.71 & 19.72 \\
$\begin{array}{l}\text { acceleration } \\
\left(\mathrm{m} / \mathrm{s}^{2}\right)\end{array}$ & -2.03 & -1.52 & 25 \\
& $\begin{array}{l}63.443 \mathrm{~s} \\
\left(2.13 \mathrm{~m} / \mathrm{s}^{2}\right)\end{array}$ & $\begin{array}{c}62.164 \mathrm{~s} \\
\left(1.71 \mathrm{~m} / \mathrm{s}^{2}\right)\end{array}$ & 2.02 \\
$\begin{array}{l}\text { Time of the } \\
\text { maximum peak }\end{array}$ & $\begin{array}{c}63.441 \mathrm{~s} \\
(-2.03 \mathrm{~m} /\end{array}$ & $62.168 \mathrm{~s}$ & \\
& $\left.\mathrm{~s}^{2}\right)$ & $\left(-1.52 \mathrm{~m} / \mathrm{s}^{2}\right)$ & 2.01 \\
$\begin{array}{l}\text { Ride comfort } \\
\text { index }\end{array}$ & 2.2107 & 2.1659 & 2.03 \\
\hline
\end{tabular}

the vehicle dynamics model shown in Figure 6 was used to calculate and analyze the influence of WPW coupled with equivalent in-phase WDD on the stability and ride comfort of the vehicle.

4.1. Hunting Stability. Hunting stability is an extremely important aspect of vehicle dynamic performance. Critical speed is the most direct indicator for hunting stability assessment. When a vehicle runs at a normal speed, it is necessary to ensure the overall stability of the vehicle system and protect it from instability; otherwise, the vehicle will snake heavily, thus affecting its operational quality and safety.

In this paper, the critical speed was calculated using the acceleration reduction method. At first, sinusoidal excitation was applied to rails on the straight line and a force was exerted on the vehicle body (The magnitude is half the weight of the vehicle body and in the opposite direction of the vehicle movement). Then, the vehicle started to move and its equilibrium position during vibration was observed. The vehicle velocity at this position was defined as the critical speed. As shown in Figure 8, the equilibrium point in condition $S 1$ occurred at $171 \mathrm{~km} / \mathrm{h}$, so the critical speed was $171 \mathrm{~km} / \mathrm{h}$.
Figure 9 illustrates the critical speed for different degrees of WPW coupled with different WDDs. The following are shown in Figure 9:

(1) It is clear from the figure that for a given WDD, increasing the degree of WPW gradually reduced the critical speed and thereby the vehicle stability. When the WDD was $-1,-0.8,-0.5,-0.2,0,0.2,0.5,0.8$, and $1 \mathrm{~mm}$, the critical speed for worn wheel profile $S 3$ decreased by $32.3 \%, 30.3 \%, 35.1 \%, 33.7 \%, 33.3 \%$, $32.9 \%, 31.5 \%, 33.8 \%$, and $36.3 \%$, respectively, compared with that for $S 1$. The rate of decrease differs slightly between different WDDs.

(2) For a given worn wheel profile, the critical speed in the presence of WDD was lower that in the absence of WDD. Besides, as the absolute value of WDD increased, the critical speed tended to decline and had a roughly symmetric distribution. This trend is most marked for $S 1$, where the critical speed for a $-1 \mathrm{~mm} \operatorname{WDD}\left(\left(D_{\text {inner }}>D_{\text {outer }}\right)\right)$ decreased by $47 \mathrm{~km} /$ h compared to the critical speed for a 0 WDD. In condition $S 3$, when WDD was $-1,-0.8,0.8$, and $1 \mathrm{~mm}$, the vehicle's critical speed was $86,92,96$, and $91 \mathrm{~km} / \mathrm{h}$, respectively, which are all below the maximum allowable speed for running along the studied line, $100 \mathrm{~km} / \mathrm{h}$. The actual maximum speed of a vehicle running on a straight line is restricted by its critical speed. If the actual speed exceeds the four critical levels, it will snake heavily and lose lateral stability, leading to passenger discomfort and even derailment in a worse-case scenario.

(3) Whether the larger-diameter wheels are on the inner side or outer side has little influence on the critical speed. As the WDD changed, the critical speed had an approximately symmetrical distribution.

The analysis above demonstrates that the critical speed tended to decline with increasing WDD and WPW. This is primarily because the presence of WDD caused the rolling wheelsets to deviate from the centerline of the track and thereby increased wheelsets' lateral displacement and angle of offset. Consequently, the geometry of wheel/rail contact was altered and the critical speed declined. Meanwhile, as the equivalent conicity increased with the increasing degree of WPW, the nonlinear critical speed of the vehicle gradually declined.

4.2. Vehicle Ride Comfort. The operational performance of trains is commonly measured by the ride comfort index, which can be graded in accordance with Table 6 .

Figure 10 demonstrates the influence of different degrees of WPW coupled with different WDDs on the vehicle's ride comfort. Figures 10(a) and 10(b) illustrate the lateral ride comfort index and vertical ride comfort index, respectively.

(1) For a given WDD, the ride comfort index tended to increase with increasing the degree of WPW in both the vertical and lateral directions. When the WDD 


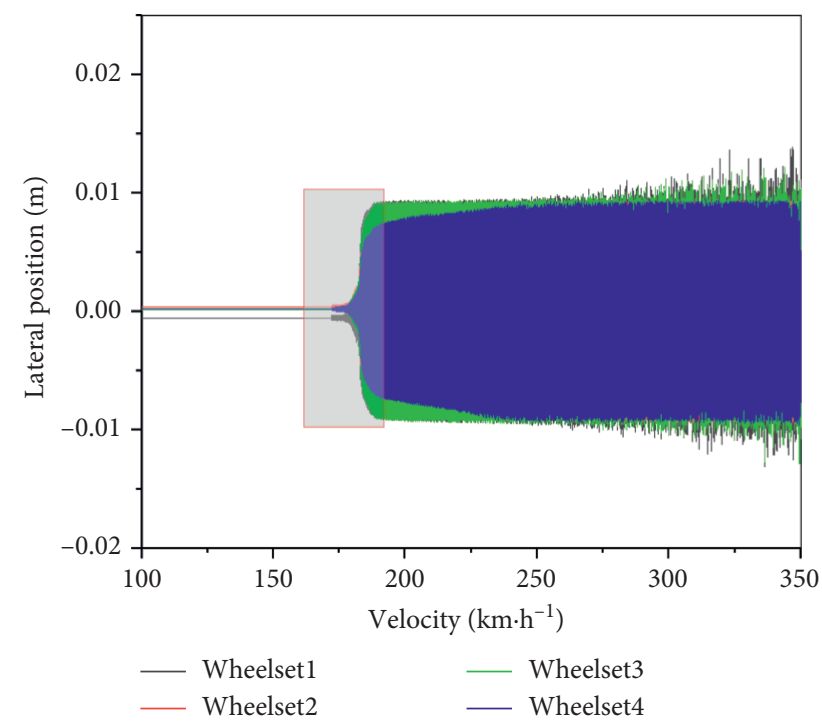

(a)

FIgure 8: Schematic diagram of critical speed. (a) Critical speed in condition S1. (b) Detail.

(b)

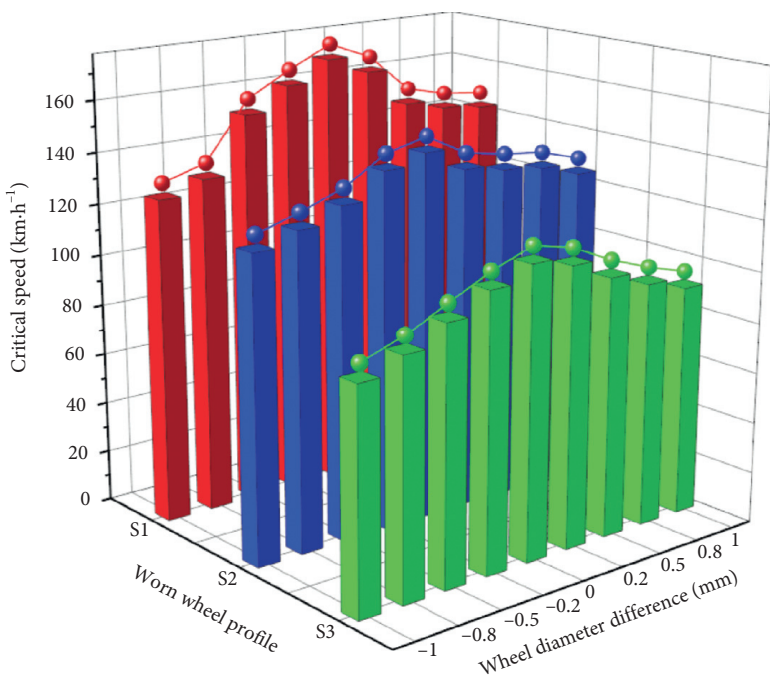

Figure 9: Critical speed.

TABLE 6: Vehicle ride comfort index and grading.

\begin{tabular}{lcccc}
\hline \multirow{2}{*}{ Grade } & \multirow{2}{*}{ Rating } & \multicolumn{3}{c}{ Ride comfort index } \\
& & Carriage & Locomotive & Freight car \\
\hline 1 & Excellent & $<2.5$ & $<2.75$ & $<3.5$ \\
2 & Good & $2.5 \sim 2.75$ & $2.75 \sim 3.10$ & $3.5 \sim 4.0$ \\
3 & Fair & $2.75 \sim 3.0$ & $3.1 \sim 4.0$ & $4.0 \sim 4.25$ \\
\hline
\end{tabular}

was $-1,-0.8,-0.5,-0.2,0,0.2,0.5,0.8$, and $1 \mathrm{~mm}$, the lateral ride comfort index for worn wheel profile $S 3$ increased $18.5 \%, 19 \%, 19.1 \%, 21.1 \%, 23 \%, 20.8 \%$, $17.2 \%, 16.9 \%$, and $15.9 \%$, respectively, compared to that for $S 1$. The corresponding increases in the vertical ride comfort index were $25.9 \%, 27.3 \%$, $30.5 \%, 38.2 \%, 45.1 \%, 41.5 \%, 39.9 \%, 38.3 \%$, and

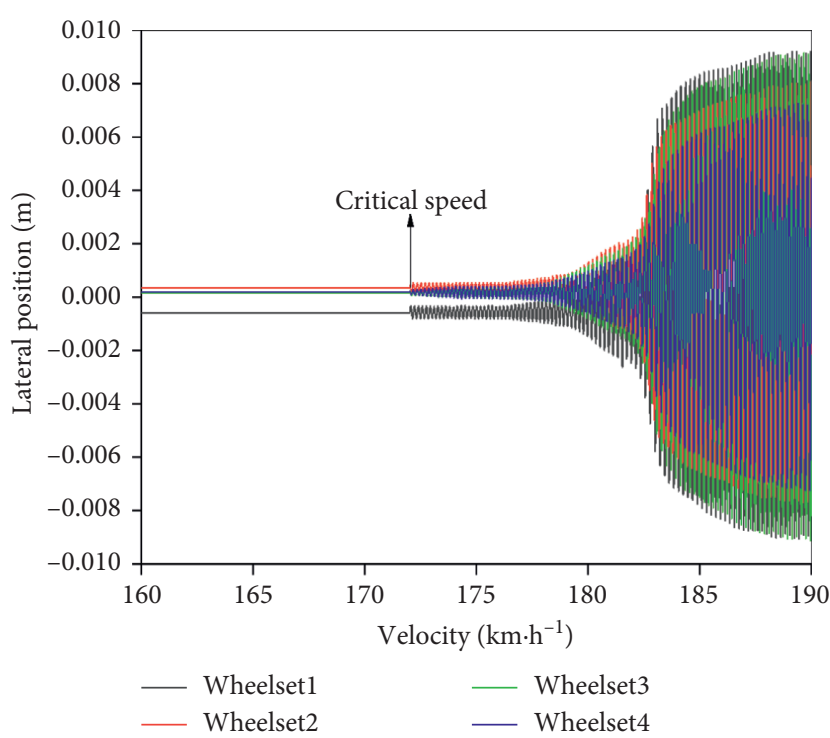

$30.6 \%$, greater than the increases in the lateral ride comfort index. Moreover, as the absolute value of WDD increased, the increase in the ride comfort index caused by profile change tended to decline slightly. This indicates that the presence of WDD can inhibit the negative effect of profile change on the ride comfort index to some extent.

(2) Figure 11 illustrates how the vibration acceleration varied with the degree of WPW when the WDD was 0 . It was found that the vertical and lateral accelerations increased with greater WPW, which is consistent with the trend in the ride comfort index described in (1).

(3) For a given worn wheel profile, as the absolute value of WDD increased, the lateral and vertical ride comfort indexes declined compared to those for 0 WDD, and their distributions are approximately symmetric. An inference is that a proper WDD can help improve the ride comfort of vehicles. In addition, the approximately symmetric distribution suggests that whether the larger-diameter wheels are on the inner side or outer side has little effect on the ride comfort index.

As the degree of WPW increased, the amplitudes of vertical and lateral accelerations expanded, increasing the ride comfort index. In the presence of WDD, the creep forces on the left and right wheels caused the wheelsets to yaw clockwise, resulting in lateral displacement of wheelsets. When equivalent in-phase WDD occurred between the front and rear wheelsets of a bogie, the front and rear wheelsets would move towards the same side, which will not cause a significant deflection of the bogie. Therefore, a very small angle of offset between the front and rear wheelsets will help improve the ride comfort of the vehicle system [33]. 


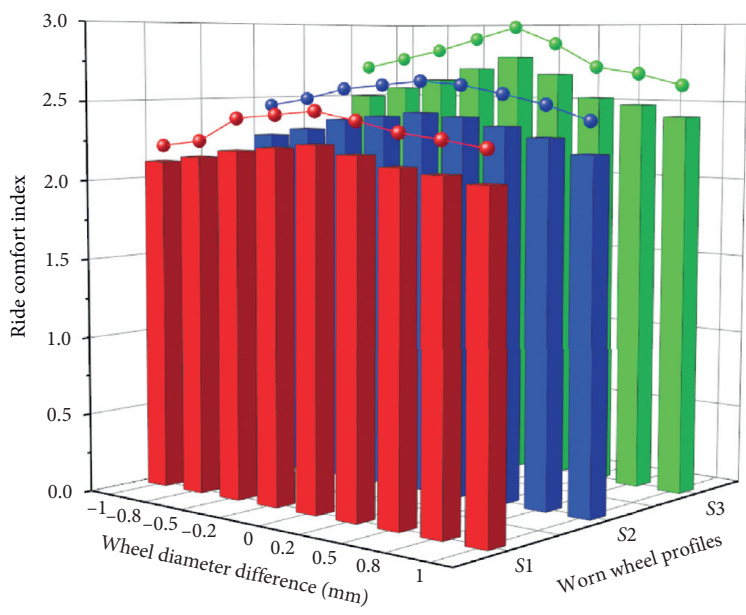

(a)

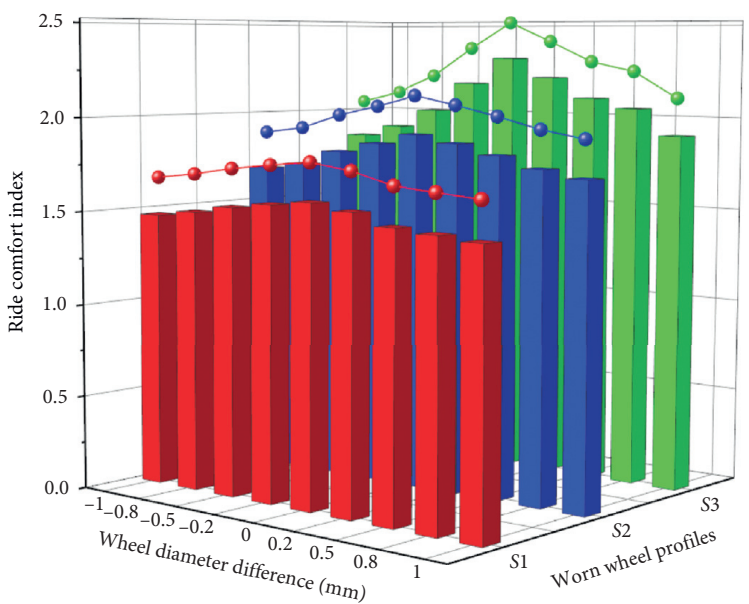

(b)

Figure 10: Ride comfort index. (a) Lateral ride comfort index. (b) Vertical ride comfort index.

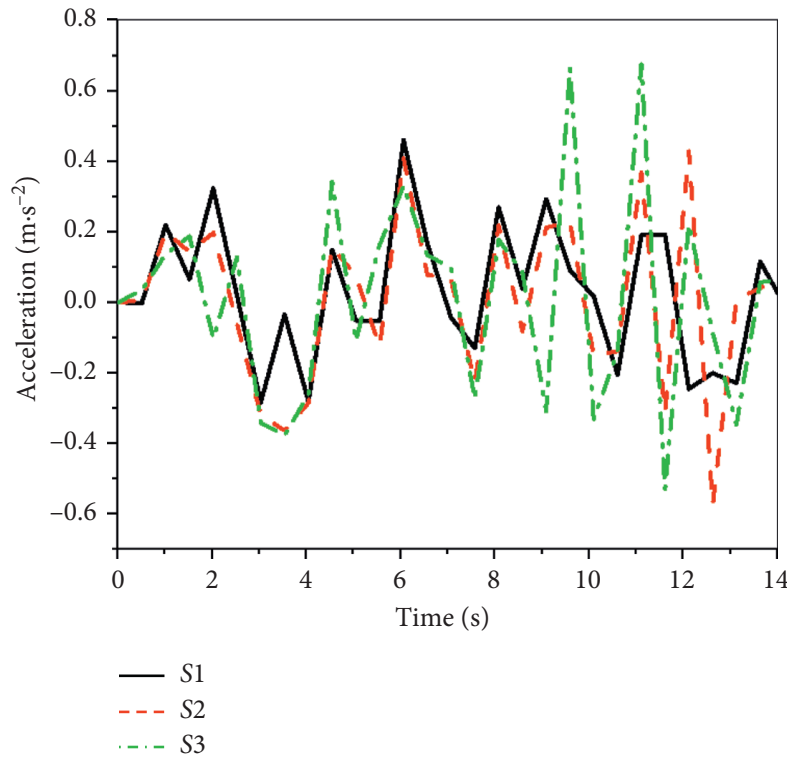

(a)

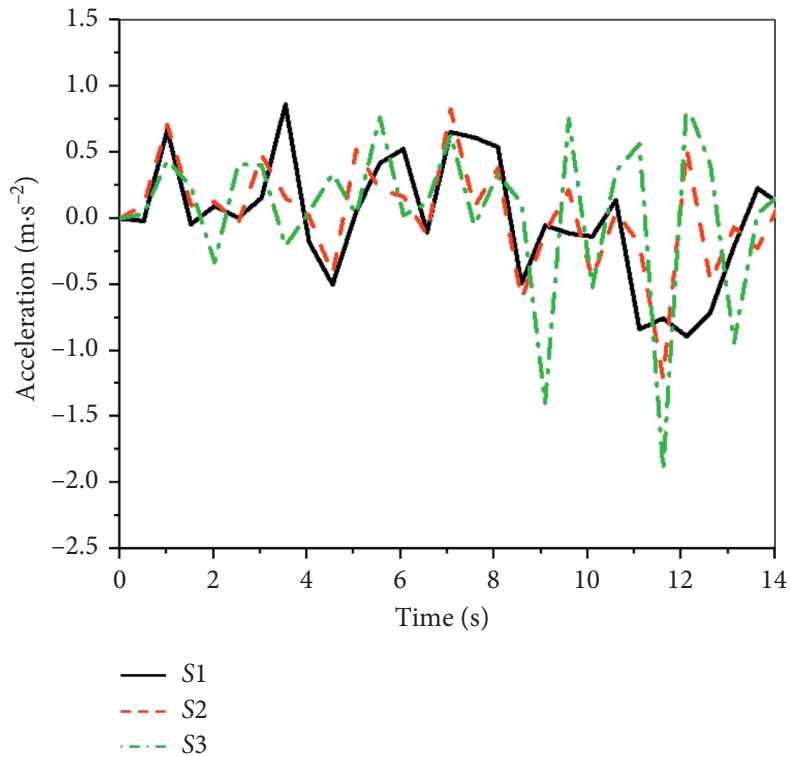

(b)

FIgURE 11: Vibration acceleration. (a) Vertical acceleration. (b) Lateral acceleration.

\section{Influence of WPW Coupled with WDD on the Vehicle's Curve Negotiation Performance}

Three worn wheel profiles for $5 \times 10^{4}, 8 \times 10^{4}$, and $14 \times 10^{4} \mathrm{~km}$ traveled (denoted as $S 1, S 2$, and $S 3$ ) and nine WDDs between $-1 \mathrm{~mm}$ and $+1 \mathrm{~mm}$ (Table 1 ) were set based on the measured data from the test vehicle, the same as in Section 4. Then, the vehicle dynamics model shown in Figure 6 was used to calculate and analyze the influence of WPW coupled with equivalent in-phase WDD on lateral wheel/rail contact force, derailment coefficient, axle lateral force, and wear index.
5.1. Wheel/Rail Lateral Force. Figure 12 shows the lateral wheel/rail contact force for different degrees of WPW coupled with different WDDs.

The following are shown in Figure 12:

(1) For a given WDD, the peak lateral wheel/rail contact force increased as the degree of WPW increased (i.e., as the wheel profile changed from $S 1$ to $S 2$ and then to S3). This increase was especially noticeable on outer wheels, where the lateral wheel/rail contact force was 1.67 times greater than that on inner wheels. Table 7 shows the increase in peak lateral wheel/rail contact force on outer wheels due to 


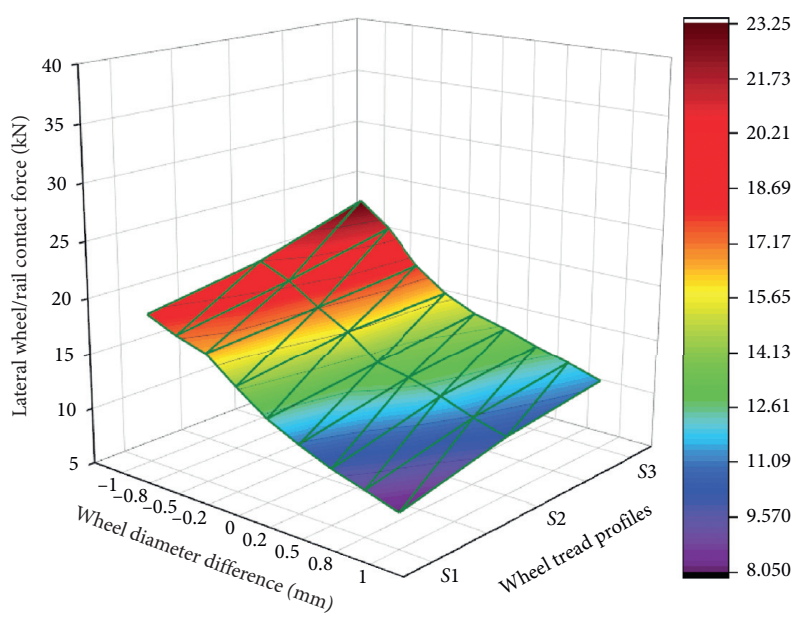

(a)

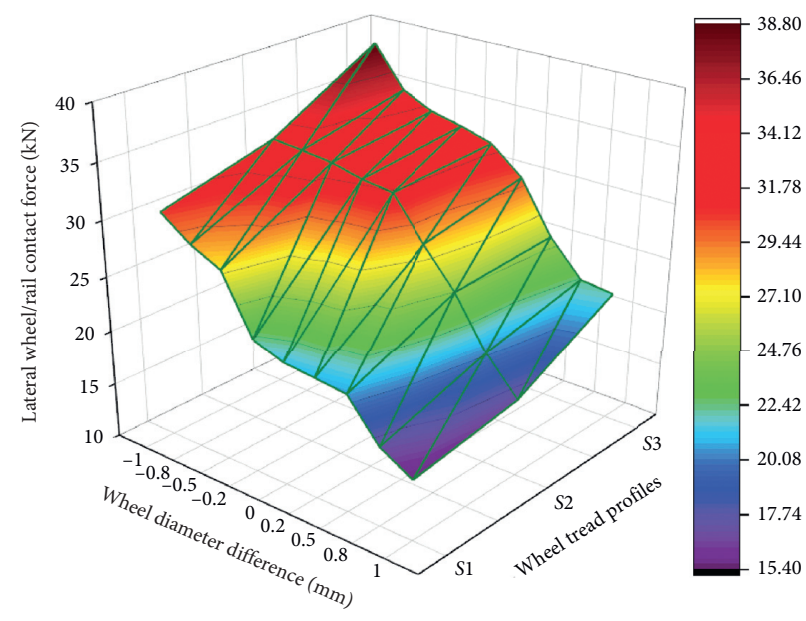

(b)

FIgURE 12: Lateral wheel/rail contact force. (a) Inner wheel (right wheel). (b) Outer wheel (left wheel).

TABLE 7: Increase in peak lateral wheel/rail contact force on outer wheels due to profile change from $S 1$ to $S 3$.

\begin{tabular}{lccccccccc}
\hline WDD & $-1(\%)$ & $-0.8(\%)$ & $-0.5(\%)$ & $-0.2(\%)$ & $0(\%)$ & $0.2(\%)$ & $0.5(\%)$ & $0.8(\%)$ & $1(\%)$ \\
\hline Increase & 26.4 & 22.4 & 23.6 & 49.5 & 52.7 & 43.5 & 23.3 & 30.1 & 41.8 \\
\hline
\end{tabular}

profile change from $S 1$ to $S 3$ for different WDD $(-1$, $-0.8,-0.5,-0.2,0,0.2,0.5,0.8$, and $1 \mathrm{~mm})$.

(2) For different worn wheel profiles, the lateral wheel/ rail contact force was relatively small when outer wheels had larger diameters than inner wheels' (WDD $>0$ ). As can be seen in Table 7 , the increase in lateral wheel/rail contact force for zero WDD was higher than those for nonzero WDD. This suggests that the presence of WDD reduced the peak lateral wheel/rail contact force and suppressed its increase due to profile change to some extent.

(3) When the larger-diameter wheels were on the inner side (i.e., WDD $<0$ ), the lateral wheel/rail contact force was relatively larger. When a $-1 \mathrm{~mm}$ WDD was coupled with profile $S 3$, the peak lateral wheel/rail contact force on the outer wheels reached up to $38.74 \mathrm{kN}$, close to the safety limit of $41.29 \mathrm{KN}$.

After wheels began to wear, highly nonlinear contact occurred between wheel and rail and wheel/rail interaction deteriorated, significantly increasing the amplitude of the wheel/rail lateral force. As the presence of WDD caused lateral movement of the wheelset, the lateral creepage between wheel and rail tended to increase. When the larger-diameter wheels were on the inner side, the lateral creep was in the same direction as the centrifugal force. When the larger-diameter wheels were on the outer side, the lateral creep was in the opposite direction of the centrifugal force, thereby reducing the wheel/rail lateral force.
5.2. Derailment Coefficient. Figure 13 shows the derailment coefficient for different degrees of WPW coupled with different WDDs.

The following can be seen from Figure 13:

(1) For a given WDD, the derailment coefficient of both the left and right wheels increased with the increasing degree of WPW, and this trend was more marked for the outer wheel (left wheel). The increases in derailment coefficient due to profile change from $S 1$ to $S 3$ for different WDDs $(-1,-0.8$, $-0.5,-0.2,0,0.2,0.5,0.8$, and $1 \mathrm{~mm}$ ) are presented in Table 8. It is clear that the increase in derailment coefficient grew sharply when the WDD reached $0.8 \mathrm{~mm}$ and $1 \mathrm{~mm}$.

(2) When the larger-diameter wheels were on the outer side (i.e., WDD $>0$ ), the derailment coefficient was relatively low, indicating that the vehicle's stability against derailment can be improved by positioning larger-diameter wheels on the outer side. When the larger-diameter wheels were on the inner side (i.e., WDD $<0$ ), the derailment coefficient was relatively high. When a $-1 \mathrm{~mm}$ WDD was coupled with the worn wheel profile $S 3$, the peak derailment coefficient was 0.84 , higher than the safety limit of 0.8 .

(3) The derailment coefficient of outer wheels (left wheels) was higher, and its peak value was 1.91 times greater than inner wheels.

The variation pattern of derailment coefficient is similar to that of wheel/rail lateral force. This is because WPW and WDD have a greater effect on wheel/rail lateral 


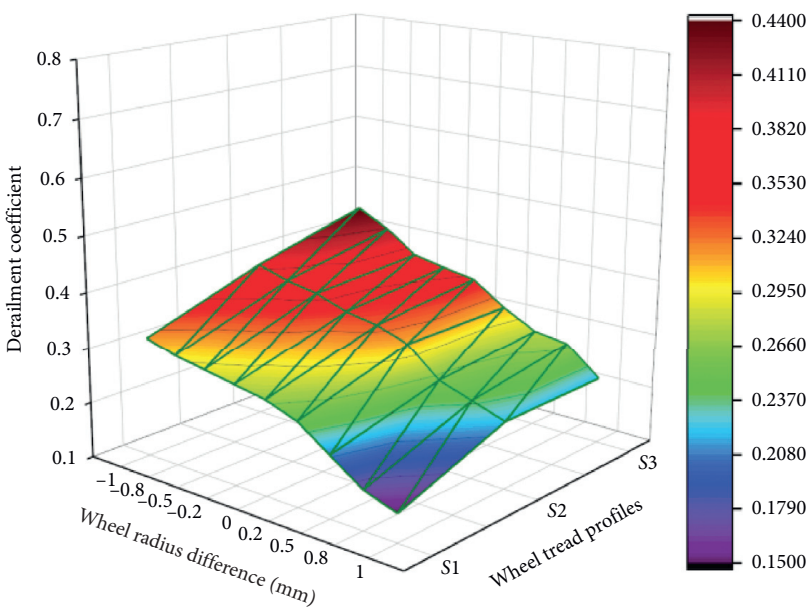

(a)

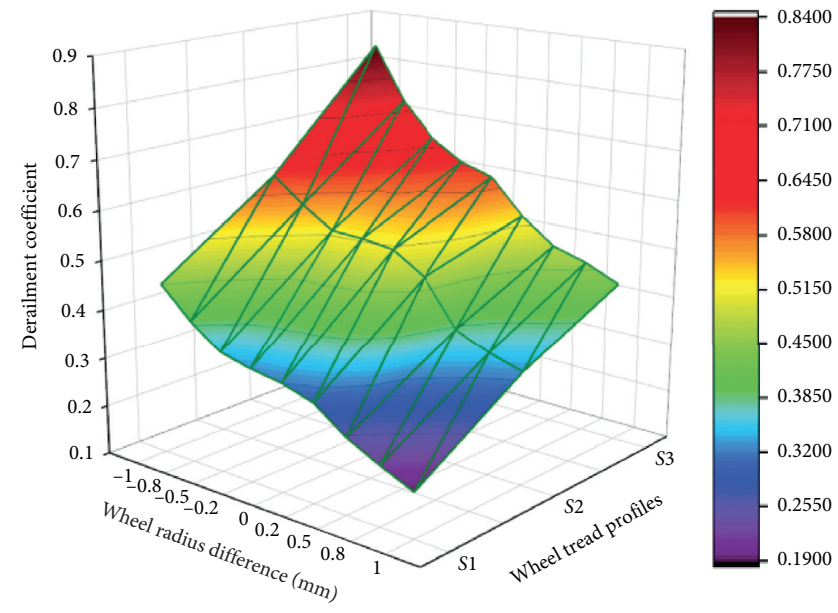

(b)

Figure 13: Derailment coefficient. (a) Inner wheel (right wheel). (b) Outer wheel (left wheel).

TABLE 8: Increase in peak derailment coefficient of outer wheels due to profile change from S1 to S3.

\begin{tabular}{lccccccccc}
\hline WDD & $-1(\%)$ & $-0.8(\%)$ & $-0.5(\%)$ & $-0.2(\%)$ & $0(\%)$ & $0.2(\%)$ & $0.5(\%)$ & $0.8(\%)$ & $1(\%)$ \\
\hline Increase & 86.3 & 86.6 & 87.4 & 87.8 & 91 & 76.7 & 89.7 & 109.1 & 125.2 \\
\hline
\end{tabular}

force than on wheel/rail vertical force, and derailment coefficient is the ratio of wheel/rail lateral force to wheel/ rail vertical force.

5.3. Axle Lateral Force. Figure 14 depicts the axle lateral force for different degrees of WPW coupled with different WDDs. As shown in the figure,

(1) For a given WDD, with the increase in the degree of WPW, the axle lateral force increased at a growing rate. The increases in axle lateral force due to profile change from $S 1$ to $S 3$ for different WDDs $(-1,-0.8$, $-0.5,-0.2,0,0.2,0.5,0.8$, and $1 \mathrm{~mm}$ ) are presented in Table 9.

(2) It is clear from Figure 14 and Table 9 that as the WDD changed from $-1 \mathrm{~mm}$ to $1 \mathrm{~mm}$ (i.e., as the difference between outer wheel diameter and inner wheel diameter increased), the magnitude and growth rate of axle lateral force declined at a decreasing rate. This suggests that when the outer wheel diameter was larger than the inner wheel diameter, the growth in axle lateral force due to increased profile wear was slowed down to some degree. If inner wheels had a greater diameter, the growth in axle lateral force would speed up.

(3) When a $-1 \mathrm{~mm}$ WDD was coupled with worn wheel profile S3, the peak axle lateral force reached $37.51 \mathrm{kN}$, which approaches the safety limit of $37.75 \mathrm{kN}$. This suggests that the vehicle exerted relatively large lateral forces on the tracks in this case, which could cause lateral track movement and even derailment.

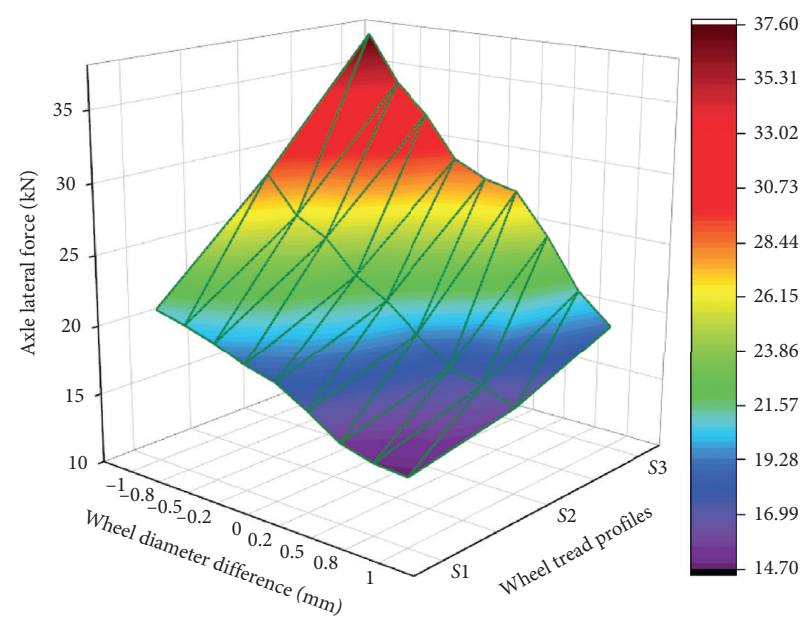

Figure 14: Axle lateral force.

Axle lateral force is mainly affected by the wheel/rail lateral force and also related to the force transferred from the bogie to the axle. The analysis results show that the variation law of axle lateral force is similar to that of wheel/rail lateral force.

5.4. Wear Index. Elkins's wear index is calculated by summing the scalar products of creep force and creepage on all contact patches.

Figure 15 depicts the wear index for different degrees of WPW coupled with different WDDs.

The following can be seen from Figure 15: 
TABLE 9: Increase in peak axle lateral force on outer wheels due to profile change from $S 1$ to $S 3$.

\begin{tabular}{lccccccccc}
\hline WDD & $-1(\%)$ & $-0.8(\%)$ & $-0.5(\%)$ & $-0.2(\%)$ & $0(\%)$ & $0.2(\%)$ & $0.5(\%)$ & $0.8(\%)$ & $1(\%)$ \\
\hline Increase & 57.4 & 52.3 & 49.2 & 45.5 & 45.1 & 43.7 & 41.7 & 36.5 & 26.9 \\
\hline
\end{tabular}

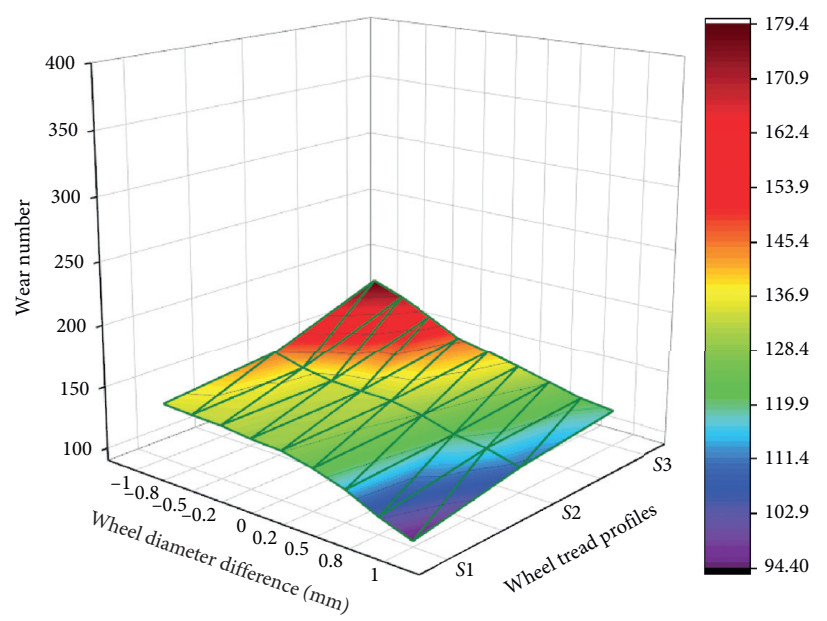

(a)

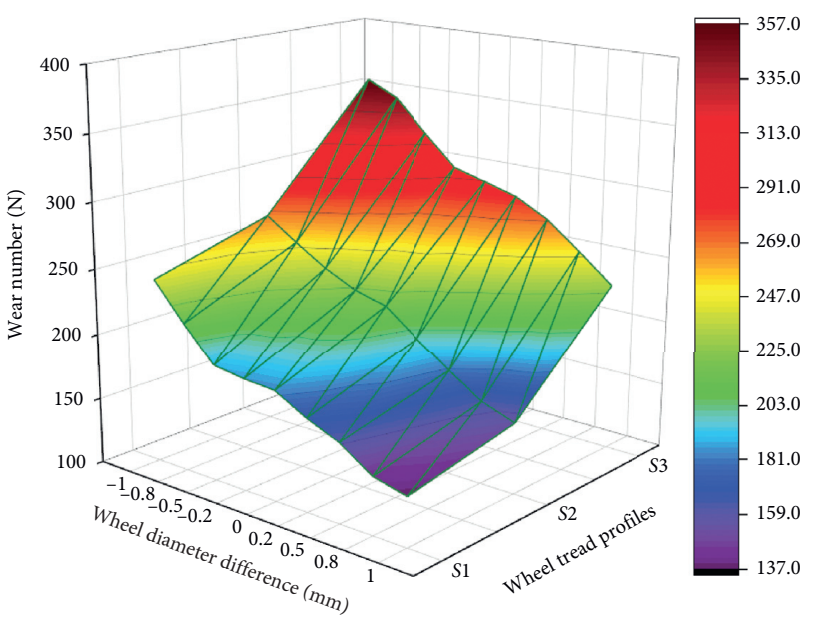

(b)

FIgURE 15: Wear index. (a) Inner wheel (right wheel). (b) Outer wheel (left wheel).

TABLE 10: Increase in the wear index of outer wheels due to profile change from $S 1$ to $S 3$.

\begin{tabular}{lccccccccc}
\hline WDD & $-1(\%)$ & $-0.8(\%)$ & $-0.5(\%)$ & $-0.2(\%)$ & $0(\%)$ & $0.2(\%)$ & $0.5(\%)$ & $0.8(\%)$ & $1(\%)$ \\
\hline Increase & 47.9 & 61.6 & 70.1 & 60.6 & 58.4 & 66.6 & 68.9 & 74.6 & 67.1 \\
\hline
\end{tabular}

(1) The wear index of both the left and right wheels increased with increasing degree of WPW. The outer (left) wheels had a greater wear index, and the peak wear index was about 1.99 times that of the inner wheels. Table 10 shows the increase in wear index of the outer wheels due to profile change from $S 1$ to $S 3$ for different WDDs $(-1,-0.8,-0.5,-0.2,0,0.2,0.5$, 0.8 , and $1 \mathrm{~mm})$.

(2) When the larger-diameter wheels were on the outer side (i.e., $\mathrm{WDD}>0$ ), the wear index was relatively low, indicating that the resistance to wheel wear can be improved by positioning larger-diameter wheels on the outer side. When the larger-diameter wheels were on the inner side (i.e., WDD $<0$ ), the wear index was relatively high. In the case where a $-1 \mathrm{~mm}$ WDD was coupled with worn wheel profile $S 3$, the wear index reached up to $356.78 \mathrm{~N}$, indicating extremely severe wheel/rail wear.

As the degree of WPW increased, the wheel/rail interaction deteriorated and wheel/rail wear increased. When the inner wheels had a larger diameter than the outer wheels, the yaw angle and lateral creepage of the wheelset increased with increasing WDD and wheel/rail wear increased under the combined action of centrifugal forces.

\section{Conclusions}

Wheel profile wear and equivalent in-phase wheel diameter difference coexist on the studied subway line. This study investigated the influence of WPW coupled with WDD on vehicle dynamics, compared the dynamic responses of outer and inner wheels, and then analyzed the vehicle's dynamic performance for different positions of the larger-diameter wheels. The study can lead to the following conclusions:

(1) The dynamic performance of the vehicle during running on a straight line can be characterized as follows:

(i) In the presence of WPW coupled with WDD, the vehicle's ride comfort index decreased as the absolute value of WDD increased. This suggests that WDD can slow down the deterioration of ride comfort index caused by increasing WPW and improve the vehicle's ride comfort to some extent. However, the coupled damage reduced the critical speed and undermined hunting stability. The critical speed for the worn wheel profile for $14 \times 10^{4} \mathrm{~km}$ was lower than the maximum allowable speed for running on a straight line $(100 \mathrm{~km} / \mathrm{h})$ when WDD was -1 , $-0.8,0.8$, and $1 \mathrm{~mm}$. 
(ii) Whether the larger-diameter wheels are on the inner side or outer side had little influence on the vehicle's critical speed and ride comfort index.

(2) The curve negotiation performance of the vehicle has the following characteristics:

(i) In the presence of WPW coupled with WDD, the vehicle showed increases in the lateral wheel/rail contact force, derailment coefficient, axle lateral force, and wear index and deterioration of curve negotiation performance when the larger-diameter wheels were on the inner side. When the larger-diameter wheels were on the outer side, the lateral wheel/rail contact force, derailment coefficient, axle lateral force, and wear index declined, indicating that the coupled damage can improve the vehicle's dynamic performance if the outer wheel diameter is larger than inner wheel diameter.

(ii) In the presence of WPW coupled with WDD, the outer wheels had significantly greater lateral wheel/rail contact force, derailment coefficient, and wear index compared to the inner wheels, and their peak values were $1.67,1.91$, and 1.99 times greater, respectively, than those on the inner side.

(iii) When the worn wheel profile for $14 \times 10^{4}$ kilometers traveled was coupled with $-1 \mathrm{~mm}$ WDD, the peak lateral wheel/rail contact force and peak axle lateral force on the outer side reached up to $38.74 \mathrm{kN}$ and $37.51 \mathrm{kN}$, respectively, which are close to corresponding safety limits. The peak derailment coefficient was 0.84 , higher than the safety limit of 0.8 . The wear index was as high as $356.78 \mathrm{~N}$, indicating that the wheels were badly worn.

(3) During the maintenance of subway vehicles, the maintenance personnel should check the coupling of different types of wheel damage in addition to wheel damage detection. Moreover, special attention should be paid to the curve negotiation performance of outer wheels when the inner wheels have greater diameters than outer wheels. After the distance traveled reaches $14 \times 10^{4} \mathrm{~km}$, the personnel should check whether the lateral wheel/rail contact force, derailment coefficient, and axle lateral force exceed the safety limits.

\section{Data Availability}

The data used to support the findings of this study are available from the first author upon request.

\section{Conflicts of Interest}

The authors declare that there are no conflicts of interest regarding the publication of this paper.

\section{Acknowledgments}

This research was funded by the National Natural Science Foundation of China (Grant no. 51975038).

\section{References}

[1] D. Cui, L. Li, H. Wang, Z. Wen, and J. Xiong, "High-speed EMU wheel re-profiling threshold for complex wear forms from dynamics viewpoint," Wear, vol. 338-339, pp. 307-315, 2015.

[2] W. J. Lu, G. Q. Tao, P. Wang et al., "Influence of wheel wear on wheel-rail contact behavior and dynamic performance of metro vehicle," Engineering Mechanics, vol. 34, no. 08, pp. 222-231, 2017.

[3] Y. M. Yao, G. F. Li, and W. C. Ding, "Influences of wheel wear on dynamics performance of vehicles based on Archard model," China Mechanical Engineering, vol. 28, no. 19, pp. 2311-2317+2324, 2017.

[4] S. Pradhan, A. K. Samantaray, and R. Bhattacharyya, "Prediction of railway wheel wear and its influence on the vehicle dynamics in a specific operating sector of Indian railways network," Wear, vol. 406-407.

[5] Y. Sun, S. Y. Zhu, and W. M. Zhai, "Influence of tread hollowworn wheel on wheel/rail interaction," Journal of Mechanical Engineering, vol. 54, no. 04, pp. 109-116, 2018.

[6] R. L. Zong, M. R. Hou, and H. M. Dai, "Study on impact of wheel rail wear on nonlinear critical speed of metro vehicles," Modern Urban Transit, vol. 7, pp. 56-60, 2018.

[7] H. L. Shi, S. Qu, D. F. Zhang et al., "Dynamic Response Performance Analysis of High-speed Trains on Track," Journal of the China Railway Society, vol. 41, no. 10, pp. 30-37, 2019.

[8] Q. Xiao, C. Li, C. Chang et al., "Research on Turnout Passing Performance of High-speed Train with Different Wheel Wear States," Journal of the China Railway Society, vol. 42, no. 08, pp. 51-59, 2020.

[9] L. Xu, D.L Cheng, C. Xu et al., "Effect of Wheel Wear on Dynamics Performance of $350 \mathrm{~km} / \mathrm{h}$ EMU," Science Technology and Engineering, vol. 20, no. 17, pp. 7046-7051, 2020.

[10] J.P. Xie, Z. Y. Chen, Y. Pan et al., "Influence of wheel harmonic wear on wheel-rail vertical force and vehicle stability," Journal of Central South University (Science and Technology), vol. 51, no. 07, pp. 2013-2020, 2020.

[11] L. Xu and W. M. Zhai, "Stochastic analysis model for vehicletrack coupled systems under joint random irregularities of wheel treads and track irregularities," Journal of the China Railway Society, vol. 42, no. 02, pp. 79-85, 2020.

[12] B. Liu and S. Bruni, "Influence of individual wheel profiles on the assessment of running dynamics of a rail vehicle by numerical simulation: a case study," Vehicle System Dynamics, pp. 1-20, 2021.

[13] K. K. Lyu, K. Y. Wang, and L. Ling, "Influence of wheel diameter difference on surface damage for heavy-haul locomotive wheels: Measurements and simulations," International Journal of Fatigue, vol. 132, pp. 1-10, 2020.

[14] S. G. Sun, L. N. Li, J. L. Zhou, and W. Li, "Influence of wheel diameter difference on safety and stationarity of vehicles crawling over the curved bridge," Applied Mechanics and Materials, vol. 209-211, pp. 2117-2120, 2012.

[15] Y. P. Jiang, M. R. Chi, C. Zhou et al., "Influence of Wheel Radius Difference Combination on the Dynamic Performance of Metro Vehicles," Lubrication Engineering, vol. 44, no. 10, pp. 115-120, 2019. 
[16] S. Yan, Y. Jiang, and H. Wang, "Analysis of Influence of Wheel Diameter Difference on Safety Performance of Locomotive," Journal of Chongqing University of Technology (Natural Science), vol. 33, no. 08, pp. 30-37, 2019.

[17] R. Chen, J. Y. Chen, P. Wang et al., "Effect of Wheel Diameter Difference on Wheel-rail Contact Geometry and Vehicle Running Behavior in Turnout Area," Journal of the China Railway Society, vol. 40, no. 05, pp. 123-130, 2018.

[18] W. Ma, R. M. Zou, and S. H. Luo, "Influence of Wheel Diameter Difference on Wheel/Rail Interaction of Locomotive under Coasting and Electric Braking Conditions," Journal of Mechanical Engineering, vol. 51, no. 14, pp. 115-121, 2015.

[19] C. Y. He, R. R Song, and W. H. Ma, "Influence of Wheel Diameter Difference to Wheel/rail Lateral Force of the Locomotive on Tangent Track," Journal of Chongqing University of Technology(Natural Science), vol. 25, no. 07, pp. 57-63, 2011.

[20] C. Wang, W. H. Ma, S. H. Luo et al., "Study on Wheel Wear of the Subway Vehicle Based on Radius Difference," Railway Locomotive \& Car, vol. 33, pp. 87-91, 2013.

[21] S. Y. Liu, Y. S. Xu, J. Zhang et al., "Influence of Wheel Diameter Difference on the Locomotive Dynamic Performance and Wheel Rail Contact," Science Technology and Engineering, vol. 17, no. 28, pp. 125-130, 2017.

[22] Z. C. Zhang, G. Li, G. F Chu et al., "Simulation Analysis of the Influence of Wheel Diameter Difference on the Locomotive Dynamic Performance," Railway Locomotive \& Car, vol. 33, no. 02, pp. 11-16, 2013.

[23] M. R. Chi, W. H. Zhang, and J. Zeng, "Influence of wheel diameter difference on the stability of vehicle system," China railway Science, vol. 6, pp. 65-70, 2008.

[24] K. Evely, O. Peeter, and W. Gui, "Cubic Spline Histopolation," Mathematical Modelling and Analysis, vol. 22, pp. 514-527, 2017.

[25] R. Zou, W. Ma, and S. Luo, "Influence of the wheel diameter difference on the wheel/rail dynamic contact relationship of the heavy haul locomotive," Australian Journal of Mechanical Engineering, vol. 16, no. 2, pp. 98-108, 2018.

[26] N. N. Wang, S. H. Luo, and W. H. Ma, "Influence of wheeldiameter difference on dynamic curving performance of vehicle system," Railway Locomotive \& Car, vol. 30, no. 02, pp. 47-49, 2010.

[27] Y. F. Zhang and J. Li, "Effect of wheel diameter difference on passing of small radius curve in mountainous track passenger train," Journal of Huaqiao University(Natural Science), vol. 39, no. 04, pp. 489-495, 2018.

[28] R. H. Li, Y. Z. Song, and H. B. Xu, "Influence of initial wheel radius difference on the dynamic performance of high-speed train," Railway Locomotive \& Car, vol. 2, pp. 14-18, 2015.

[29] P. Han, W. H. Zhang, Y. Li et al., "Influence of wheelset wear and wheel radius difference on dynamics performances of high-speed train," Journal of Traffic and Transportation Engineering, vol. 13, no. 06, pp. 47-53, 2013.

[30] A. Zhu, C. Fu, J. Yang et al., "Research on the wheel wear of metro vehicles based on the time-varying passenger flow," Industrial Lubrication and Tribology, vol. 71, no. 9, pp. 1038-1046, 2019.

[31] J. Wang, J. Yang, Y. Zhao, Y. Bai, and Y. He, "Nonsmooth dynamics of a gear-wheelset system of railway vehicles under traction/braking conditions," Journal of Computational and Nonlinear Dynamics, vol. 15, no. 8, 8 pages, 2020.

[32] X. M. Zhang, X. B. Xie, and S. B. Yang, "Author Index," Vehicle Thermal Management Systems Conference and Exhibition (VTMS10), vol. 29, pp. 661-663, 2011.
[33] M. R. Chi, W. H. Zhang, J. Zeng et al., "Influence of wheeldiameter difference on running security of vehicle system," Journal of Traffic and Transportation Engineering, vol. 8, no. 5, 2008. 